\title{
Information systems for the manufacturing supply chain management
}

\author{
Qian Shi \\ Institute of Logistics Engineering \\ Wuhan University of Technology \\ Wuhan, China \\ 215632967@qq.com
}

\author{
Qingying Zhang \\ Institute of Logistics Engineering \\ Wuhan University of Technology \\ Wuhan, China \\ kathy8899@126.com
}

\author{
Zhengguo Wang \\ Institute of Logistics Engineering \\ Wuhan University of Technology \\ Wuhan, China \\ zgwang@whut.edu.cn
}

\begin{abstract}
Information is one of the crucial factors of supply chain management, as well as manufacturing industry. The requirements of manufacturing supply chain management, the exchange of information between enterprises are stated, system architecture and function are built, so as to find a way to optimize the manufacturing supply chain.
\end{abstract}

Keywords-supply chain; manufacturing supply chain; information system

\section{MANUFACTURING SUPPLY CHAIN MANAGEMENT}

The main manufacturing supply chain as the core of large-scale manufacturing gets many raw material suppliers, small and medium-sized generic parts manufacturers and dedicated parts manufacturing companies, logistics companies, distributors, retailers and other economic activities together into a whole.

In recent years, the manufacturing industry is getting increasingly supply-chainized, and the competition is no longer between the manufacturing companies, but the supply chains, so manufacturing supply chain management is mentioned and focused gradually.

Manufacturing supply chain includes many related areas of procurement, manufacturing, distribution, retailing, which is complex and complicated. An internal management information system of a large-scale manufacturing enterprise is usually unable to fulfill the requirements of the manufacturing supply chain, especially when the chain getting much longer in the directions of up and down streams [1]. The overall planning of the management information system is not limited within the manufacturing enterprise, but in a wider view and higher stand around manufacturing supply chain management.

\section{MANUFACTURING SUPPLY CHAIN MANAGEMENT INFORMATION SYSTEM REQUIREMENTS}

In order to respond quickly to the changes of market demand, the manufacturing supply chain should take information system as a powerful tool, which is quite different from the traditional one used in the individual company. The main differences are as follows:

\section{A. Integration requirements}

Manufacturing supply chain involved many suppliers, manufacturers, distributors, retailers and other members of the chain. Each of them has a separate information system of his own, which is developed at different times according to the respective demands. This results in the problems and obstacles in protocols, interfaces, safety requirements, the type of database, programming model and other aspects. The manufacturing supply chain management information systems therefore need to integrate all members of the chain and requirements.

\section{B. Collaborative requirements}

Compared with a single manufacturing enterprise, a manufacturing supply chain emphasizes much on the ability to speedy respond to demand changes of the market and users. Information becomes a significant driving force of collaborating among member companies in the manufacturing supply chain[2]. To seek mutual convergence between member enterprises and to operate efficiently, supply chain management information system itself requires a system of information collaboration. Manufacturing supply chain management information systems need to get all members of the corporate management information system in the collaborative manufacturing supply chain, and rapidly pass and handle a wide variety of dynamic information, such as members of the respective private enterprise market information, information of product development, production planning, inventory, sales, etc.

\section{MANUFACTURING SUPPLY CHAIN MANAGEMENT INFORMATION SYSTEM DESIGN}

\section{A. System Architecture}

With the development and the widely application of network technology, internet globalization and Web-based technologies, the advantage of Web services based on XML technology to solve the problems mentioned above is considered to be available. Because XML is a crossplatform, has nothing to do with the specific language, so it is able to integrate members of the chain information systems developed in different languages, and is easier to be used, and cheaper than the platform of Electronic Data Interchange (EDI).A manufacturing supply chain management information system (MSCMIS) is proposed. The framework is shown in Figure 1.

The architecture of MSCMIS consists of the following components: 
(1) Database Management System (DBMS, as usually abbreviated). It is responsible for the management of the local data of the member companies of the chain, including the database establishment, and the raw data input.

(2) Enterprise Database (EDBS). It stores the local data of the member companies of the manufacturing supply chain, including raw materials, information, products, and production information, as part of the manufacturing supply chain distributed database

(3) Knowledge Development Tool (KDT). On the wealth of knowledge in the manufacturing supply chain knowledge base, the system identifies potential business knowledge automatically, and then makes predictions. New knowledge found by KDT can be used to guide members of the chain to operate their business, also can be immediately added to the knowledge base of the system.

(4) Workflow Management System (WMS). It is the key part of the manufacturing supply chain management information system, responsible for business process modeling, execution and monitoring. Workflow management procedures work based on the command of the member companies of the chain, according to the rules which stored in the knowledge base to analyze the formation of workflow and to coordinate communication between members of the chain and to accomplish a enterprise-class management.

(5) Manufacturing Supply Chain Knowledge Base (MSCKB). It stores the public knowledge of the supply chain and the cooperation agreement between the enterprises, so as to support the manufacturing supply chain workflow to execute smoothly .

(6) Enterprise Management Information Systems (EMIS). Responsible for specific processing manufacturing supply chain member companies of the local business activities, it is mainly applied to input business data, query, storage, print and maintenance. It is part of the management information system for distributed manufacturing supply chain[3].

(7) Browser. The browser is an information system interface, which connects a large number of raw material suppliers, small and medium-sized the common parts and dedicated pieces manufacturing companies, logistics companies, distributors, retailers and large manufacturing companies.

(8) Web Server. When the web browsers of many raw material suppliers, small and medium-sized the common parts and private parts manufacturing companies, logistics companies, distributors, retailers are connected to the web server of the large-scale manufacturing enterprises and to make a request for the files, the web server processes the request, sends the file to the browser, and tells the browsers how to view the files via additional messages[4].

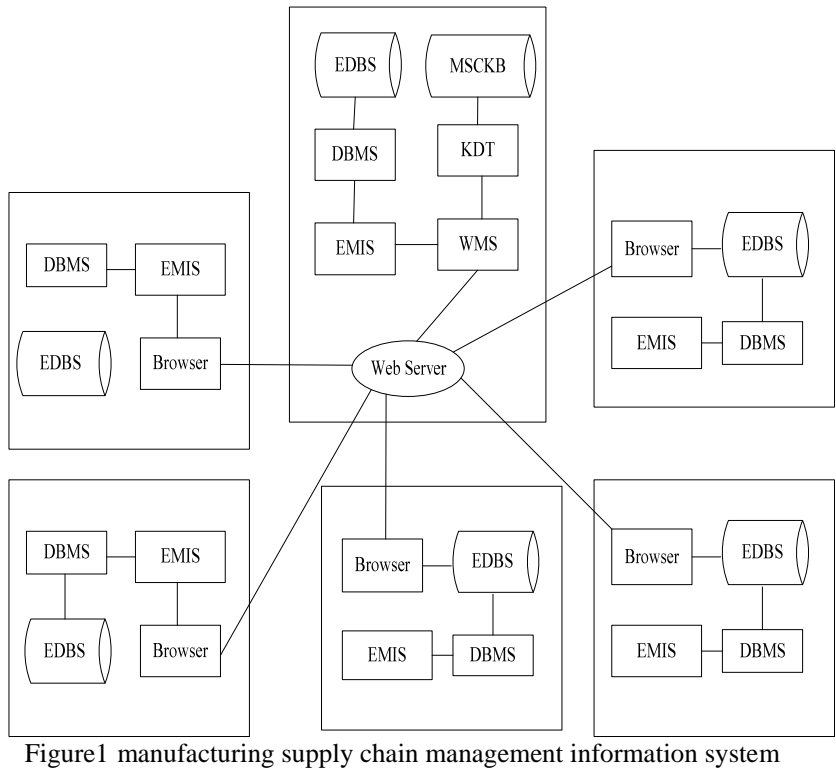

\section{B. Function and Structure}

The functional structure of MSCMIS is described below:

(1) System data management. It includes enterprise database management, and manufacturing supply chain management of knowledge, concretely refers to the treatment of data, models, methods, rules, modify, delete, and other maintenance operations.

(2) The supplier management. The main job of this part is to evaluate manufacturing supply chain management information system of raw material suppliers, small and medium-sized general and private parts manufacturing companies, and quality, price, timely delivery rate of the raw materials and components for general and special parts [5] and to manage them dynamically.

(3) Vendor management. The system estimates the multifarious distributors and retailers, and their location, marketing capabilities, credit, and financial condition, and selects the suitable ones among them.

(4) Order and logistics management. The system judges the third-party logistics enterprises, monitors and controls the orders and contracts, and governs the inventory and logistics[6].

(5) Financial and asset management. Tracking cash flow of the system and doing financial settlement between the member companies of the manufacturing supply chain timely, and managing the acquisition, depreciation and replacement of fixed assets, are all the tasks of the system.

(6) Plan and R\&D management. Manufacturing supply chain management information system provides the plan of business preparation to supply chain, checks and adjusts the supply chain planning, and manages new product research and development activities of the manufacturing supply chain management. 


\section{CONCLUSION}

With the development of the manufacturing industry, the competition between the manufacturing industries is becoming more intensive. The optimization of the manufacturing supply chain has become the key point of competition. The system improves the information sharing mechanism obviously, promotes the exchange of information between enterprises, reduces information delay and the loss, and optimizes the supply chain network definitely.

\section{ACKNOWLEDGMENT}

Supported by "the Fundamental Research Funds for the Central Universities”,2011-IV-061.

\section{REFERENCES}

[1] S.J.Hwang and S.Y.Lee:Mater. Sci. Forum Vol. 119-131 (2008), p. 594

[2] K.L. Choy and Stephen W.K. Ng: Mater. Sci. Forum Vol. 532-533 (2006), p. 1092

[3]Rogerio Odivan Brito Serrão and Paulo Roberto Tavares Dalcol. Analyzing the Influences of the Buyer-Supplier Relationship on the Manufacturing Flexibility[J].Brazilian Journal of Operations \& Pro duction Management, 2010,12(1):18-19.

[4] Lan H. Supply chain management integration risk control analysis[J].commercial era, 2010,19(31):21-22.

[5] D.L. Du and Ju Q. H.Y. Zhao. Risk assessment study of manufacturing green supply chain based on Grey Theory[C].// International Conference on Information Systems for Crisis 